\title{
Qualitative Evaluation of Factors Inducing Environmental Pollution of the Sandy Beaches of Jeju Island Using Styrene Oligomers
}

\author{
Bum Gun Kwon ${ }^{1,+\odot} \cdot$ Jea-Jun $\mathrm{Ko}^{2 \oplus} \cdot$ Jeong-Hun Park ${ }^{2,+}$ \\ 'Department of Bioenvironmental \& chemical Engineering, Chosun College of Science \& Technology, 309-1, Philmundaero, \\ Dong-gu, Gwangju 61453, Republic of Korea. \\ 2Department of Environment and Energy Engineering, Chonnam National University, 77 Yongbong-ro, Buk-gu, Gwangju 61186, \\ Republic of Korea.
}

(Received September 14, 2021; Revised December 1, 2021; Accepted December 1, 2021)

Objectives: Plastic pollution is a very important environmental issue in Korea as well as abroad. The objective of this study is to evaluate the internal and external factors that cause pollution of the coastal environment of Jeju Island using styrene oligomers (SOs) originated from polystyrene (PS) plastic.

Methods: In order to achieve the above objective, this study is conducted to quantitatively measure the concentration of 12 individual SOs chemicals, through gas chromatography/mass spectroscopy (GC/MS) analyzing seawater and beach sand samples around sandy beaches in Jeju Island. This study evaluates the degree of environmental pollution according to internal or external factors of the sandy beach by using the physicochemical characteristic that SOs species are adsorbed on the surface of sand particles.

Results and Discussion: The average concentration of SOs in the beach sand of Jeju Island ranges from a minimum of $9.80 \mathrm{ng} / \mathrm{g}$ to a maximum of $13.62 \mathrm{ng} / \mathrm{g}$, and the average concentration of SOs in seawater is relatively low with a constant 0.05 to $0.11 \mu \mathrm{g} / \mathrm{L}$. Although the concentration distribution of SOs species differs considerably depending on the sample collected, the concentration of SOs decreases in the order of styrene trimers (7 isomers) $>$ styrene dimers (4 isomers) $>$ styrene monomer. As a result of monitoring, the concentration of SOs at the sandy beaches of Jeju Island is much higher in the beach sand than in the seawater. This result means that the major beaches of Jeju Island can be polluted mainly by internal factors (e.g. population density, number of travelers according to population movement, and so on), because SOs species are adsorbed on the surface of the sand particles and their mobility is limited.

Conclusions: This study shows that the sandy beaches of Jeju Island are mainly polluted by internal factors. It is thought that the pollution degree of the sandy beaches is the highest in the order of Gwakji Beach < Samyang Beach, Hamdeok Beach, Pyoseon Beach < Ihoteho Beach, Sagye Beach < Seopjikoji Beach, Gimnyeong Beach, and Hyeopjae Beach. This study is expected to contribute to the evaluation of the causes of plastic pollution in the coastal environment of Jeju Island.

Keywords: Plastic pollution, polystyrene, styrene oligomers, micro-plastics, nano-plastics, monitoring.

The Korean text of this paper can be translated into multiple languages on the website of http://jksee.or.kr through Google Translator.

\footnotetext{
Corresponding author

E-mail:kwonbg0@daum.net or kwonbg@est.ac.kr

Tel: 062-230-8833 Fax: 062-230-8501

E-mail: parkjeo1@jnu.ac.kr

Tel: 062-530-1855 Fax: 062-530-1859

${ }^{*}$ These authors contributed equally to this work.
} 


\title{
연구논문
}

\section{스타이렌 올리고머를 이용한 제주도 모래 해변의 환경오염을 유발하는 요인의 정성적 평가}

\author{
권범근 $^{1,+\odot ~} \cdot$ 고재준 $^{2} \cdot$ 박정훈 $^{2+\oplus}$ \\ ${ }^{1}$ 조선이공대학교 생명환경화공과 \\ ${ }^{2}$ 전남대학교 환경에너지공학과
}

목적: 플라스틱 오염은 해외뿐만 아니라 국내에서도 매우 중요한 환경적 이슈이다. 이 연구의 목적은 polystyrene (PS) 플라스틱에서 유래된 styrene oligomers (SOs)를 이용하여 제주도 연안 환경의 오염을 유발하는 내·외부 요인 을 평가하는 것이다.

방법: 상기 목적을 달성하기 위해 이 연구는 제주도 내 주요한 모래 해변을 중심으로 주변 해수와 해사 시료를 채 취하여 gas chromatography/mass spectroscopy $(\mathrm{GC} / \mathrm{MS})$ 로 12종 개별 SOs 화학종의 농도를 정량적으로 분석한다. 이 연구는 SOs 화학종이 갖는 물리·화학적 특성상 모래 입자 표면에 흡착되는 성질을 이용하여, 제주도 해변의 내 부 또는 외부 요인에 따른 환경 오염도를 평가한다.

결과 및 토의: 제주도 해변의 해사에서 SOs 평균 농도는 최저 $9.80 \mathrm{ng} / \mathrm{g}$ 에서 최대 $13.62 \mathrm{ng} / \mathrm{g}$ 으로, 해수에서 $\mathrm{SOs}$ 평균 농도는 비교적 일정한 $0.05 \sim 0.11 \mu \mathrm{g} / \mathrm{L}$ 로 낮았다. 채취된 시료에 따라 $\mathrm{SOs}$ 개별 화학종의 농도 분포가 상당 한 차이가 나지만, 대체로 7종의 styrene trimers $>4$ 종의 styrene dimers $>$ styrene monomer 순으로 농도가 감소하 였다. 제주도 해변에서 SOs 농도는 해수보다 해사에서 매우 높았다. 이 결과는 SOs 화학종이 모래 입자 표면에 흡 착되어 이동성이 제한적이어서 제주도의 주요 해변이 주로 제주도 내부 요인(예, 인구 밀도, 인구 이동에 따른 여 행객 수 등)에 의해 오염될 수 있음을 의미한다.

결론: 이 연구는 제주도 모래 해변이 주로 내부 요인에 의해 오염되는 것으로 보인다. 모래 해변의 오염도는 곽지 해변 < 함덕 해변, 삼양 해변, 표선 해변 < 이호테우 해변, 사계 해변 < 섭지코지 해변, 김녕 해변, 협재 해변 순으 로 오염도가 클 것으로 생각된다. 이 연구가 제주도 해안 환경에서 플라스틱 오염의 원인을 평가하는데 기여할 것 으로 기대된다.

주제어 : 플라스틱 오염, 폴리스타이렌, 스타이렌 올리고머, 마이크로플라스틱, 나노플라스틱, 모니터링

\section{1. 서론}

버려진 플라스틱으로 인한 해양 환경의 오염 문제가 해외뿐 만 아니라 국내에서도 큰 주목을 받고 있다. ${ }^{1-4)} 1940$ 년대 대량 생산이 시작된 이래로, 플라스틱의 지구적 생산량은 1950년 170 만 톤에서 2014년 3억 1,100만 톤으로 계속 증가한 것으로 알려지고 있다. ${ }^{5)}$ 2010년 폐플라스틱 발생량은 2억 7,500만 톤 으로 이르는 것으로 추산되며, 이중 해양환경에 축적된 폐플 라스틱의 양은 $480 \sim 1,270$ 만 톤으로 예측된다. ${ }^{6)}$ 특히, 나노 $(\mathrm{nm})$ 와 마이크로 $(\mu \mathrm{m})$ 플라스틱(micro- and nano-plastics)은 지구의 심해를 비롯한 남, 북극 등 거의 모든 지구 환경에서 발견되고 있다. ${ }^{7)}$ 따라서, 해양환경에서의 나노/마이크로 플라
스틱으로 인한 환경오염은 매우 중대한 인류의 문제이다. 해양으로 버려진 플라스틱은 미세한 크기의 나노/마이크로 플라스틱으로 부서지게 되고, 이들은 서로 상호 얽히거나, 섭 취로 해양 야생 동물에게 질식과 같은 죽음을 초래하기도 한 다. ${ }^{717)}$ 또한, 해양환경에서 나노/마이크로 플라스틱를 포함한 각종 플라스틱 조각은 그 표면에 유해성 물질로 여겨지는 잔 류성유기화합물(POPs)을 흡착하거나 유해성이 의심스러운 플라스틱 첨가제를 운반하는 매체로도 활용되는 것으로 보고 된다. ${ }^{7-9)}$ 그러므로 폐플라스틱으로 인한 해양환경의 오염 문 제를 정성적, 정량적으로 조사하는 것은 매우 중요하다.

기존 폐플라스틱인 나노/마이크로 플라스틱 연구는 전형적 인 지표인 단위면적당 미세한 크기의 나노/마이크로 플라스틱 
개수를 조사하는 시각적 계수법(visual counting technique)을 주로 사용했다. ${ }^{14,15)}$ 최근 개선된 연구에서는 더욱 미세해진 나노/마이크로 플라스틱 크기, 색과 모양을 고려한 단위 면적 당 나노/마이크로 플라스틱 개수로 표현되며 이를 고려하여 나노(마이크로 플라스틱의 발생원을 추정하기도 한다. ${ }^{18)}$ 하지 만 Jambeck et al. (2015) ${ }^{6}$ 에 따르면, 나노/마이크로 플라스틱 입자에 대한 시각적인 계수법은 나노/마이크로 플라스틱의 발 생원을 추적할 수 없다. 특히, 자연적 풍화 과정을 거쳤거나 인위적 사용 혹은 파쇄로 인해 생겨난 미세한 나노/마이크로 플라스틱 입자가 해양환경에서 효과적으로 제거되는 저감 전 략을 수립하거나 환경오염도에 관한 정책적 영향을 평가하기 위한 효과적인 방안도 제공하지 못한다.

무엇보다도, 나노/마이크로 플라스틱 입자는 방대하게 분 포할 뿐만 아니라 해류 흐름과 계절적 요인으로 인해 나노/ 마이크로 플라스틱 입자가 해안에 축적되는 패턴을 평가하 기가 어렵다. 기존에 제시된 일련의 연구를 통해, 나노/마이 크로 플라스틱 입자의 수가 여전히 증가하고 있다거나 안정 화되어 있는지에 관한 궁금증 또한 증대되고 있다. 예를 들 어, 나노/마이크로 플라스틱 입자가 공간적, 시간적 변동으 로 인한 불균형한 분포 ${ }^{19}$ 이기 때문에 모니터링된 대부분의 나노/마이크로 플라스틱 입자의 시각적인 계수법은 해양환 경에서 정확한 플라스틱 오염의 정도를 나타내기에는 제한 적일 수 있다.

해양 환경문제로 나노/마이크로 플라스틱 해양오염에 대한 상당한 우려에도 불구하고, 어떤 특정 지역 내의 나노/마이크 로 플라스틱 오염도를 평가하고 이 오염도를 줄이려는 저감 전략을 수립하고 평가할 필요가 있다. 기존 연구는 나노/마이 크로 플라스틱 오염도가 해당 지역에서 모니터링 위주로 수행 되어 해당 지역의 내부 아니면 외부 요인에 의해 유래된 것인 지에 관한 연구는 거의 수행되지 않았다. ${ }^{20}$ 최근 환경에 버려 진 polystyrene (PS) 플라스틱에서 유래된 스타이렌 올리고머 (styrene oligomers, SOs)는 해수보다 주로 해변 모래 입자에 흡착된 형태로 존재하는 것으로 모니터링되었다. ${ }^{18,20-24)}$ 이들 연구는 모래 표면에 존재하는 SOs가 다른 지역으로의 이송이 제한적이어서 태평양 연안 환경의 오염을 유발하는 내·외부 요인을 평가하는 지표로 활용되었다.

이 연구의 목적은 제주도 연안 환경의 오염을 유발하는 내· 외부 요인을 정성적으로 평가하는 것이다. 이 목적을 달성하 기 위해 이 연구는 제주도 내 주요한 모래 해변을 중심으로 해수와 해사 시료를 채취하여 과학적인 정량적인 조사를 수 행하였다. 제주도 해변에서 채취된 해수와 해사 시료는 PS 플라스틱 오염의 지표로서 SOs의 농도를 gas chromatography /mass spectroscopy (GC/MS)을 이용하여 정량적으로 분석하 였다. Table 1에서 나타낸 바와 같이, 이들 SOs는 7종의 이성 질체를 갖는 스타이렌 트리머(styrene trimers, ST), 4종의 이 성질체를 갖는 스타이렌 다이머(styrene dimers, SD), 스타이
렌 모노머(styrene monomer, SM)로 구성된다. 이 연구는 SM, $\mathrm{SD}$ 및 ST의 개별 화학종의 농도의 합을 $\mathrm{SOs}$ 농도로 후술하고 자 한다.

\section{2. 재료 및 방법}

\section{1. 시약 및 재료}

12 종의 SOs 분석을 위해 사용한 표준물질 중 SM은 Sigmaaldrich (St. Louis, USA)에서, 그 외 나머지 SDs와 STs 표준물 질은 Wako chem. (Tokyo, Japan)에서 구매하였다. 또한, SOs 를 정량하는데 필요한 적절한 3종의 내부표준물질(internal standard, IS)은 모두 AccuStandard (New haven, USA)에서 구 매하였으며, 구체적인 SOs 화학종별 적절한 IS는 이 연구의 2.4절에서 후술하려고 한다.

실험에 사용한 용매는 dichloromethane (DCM) (Merck KGaA, darmstadt, Germany)을, surrogate는 biphenyl (BP) (Wako Chem., Tokyo, Japan)을 각각 구매하여 사용하였다. GC/MS 분석과 유리 재질의 실험 도구를 세척하기 위해 벤젠과 메탄올 (Merck KGaA, darmstadt, Germany)이 사용되었고, 이들 용매 는 모두 reagent grade 등급이었다. 수분 제거용 sodium sulfate anhydrous $\left(\mathrm{Na}_{2} \mathrm{SO}_{4}\right)$ 시약은 Extra Pure (DUKSAN, Ansan, Korea) 등급을 사용하였다.

\section{2. 시료채취 위치 및 방법}

Fig. 1에 제시한 바와 같이, 이 연구에서 사용된 해수와 해사 시료는 10곳의 제주도 모래 해변에서 2018년부터 2020년까 지 3 년간 채취되었다. 시료 채취는 매년 여름과 겨울에 정기 적으로 이루어졌고, 필요할 경우 봄이나 가을에 부정기적 시 료 채취가 이루어졌다. 시료 채취 방법은 기존에 수행된 연구 를 참조하여 수행되었다. ${ }^{1820-24)}$ 간략하게 언급하자면, 해수 시료는 해변을 따라 수심 약 $40 \mathrm{~cm}$ 깊이에서 $2 \mathrm{~L}$ 부피의 stainless steel 재질의 Beaker로 채취되었고, 곧바로 이 해수 시료 $2 \mathrm{~L}$ 가 유리 재질의 분별 깔때기로 이송되었다. 이송된 해수 시료에 surrogate로 BP $(1 \mathrm{mg} / \mathrm{L}) 30 \mu \mathrm{L}$ 를 가하여 DCM 용매로 수회 추출하였다. 이 추출은 DCM $25 \mathrm{~mL}$ 로 약 10 분 간 격렬하게 분별 깔때기를 흔들어 추출하였으며, 이 과정을 4 회 반복하여 총 $100 \mathrm{~mL}$ 의 DCM 용액으로 해수 시료를 추출 하였다.

모래 시료는 해변의 표면에 존재하는 모래 약 $100 \mathrm{~g}$ 을 채취 되었다. 이후 시료를 현장에서 잘 혼합하여 유리 용기에 보관 한 후 실험실로 옮겨 실험을 진행하였다.

시료의 채취와 추출 과정에서 불필요한 오차를 없애기 위해 플라스틱 재질이 포함된 실험기구와 장비를 사용하지 않았다.

\section{3. 전처리 방법}

해수와 해사 시료의 전처리 방법은 이전 연구에서 상세하게 
Table 1. Chemical names, abbreviation, CAS No., molecular formula, mas, chemical structure. ${ }^{25)}$

\begin{tabular}{|c|c|c|c|c|c|}
\hline Chemical name & Abbreviation & CAS No. & Molecular formula & Molecular mass & Chemical structure \\
\hline Styrene monomer & SM & $100-42-5$ & $\mathrm{C}_{8} \mathrm{H}_{8}$ & 104.15 & \\
\hline 1,3-diphenyl propane & SD-1 & $1081-75-0$ & $\mathrm{C}_{15} \mathrm{H}_{16}$ & 196.29 & \\
\hline 2,4-diphenyl-1-butene & SD-2 & $16606-47-6$ & $\mathrm{C}_{16} \mathrm{H}_{16}$ & 208.30 & \\
\hline cis-1,2-diphenyl cyclobutene & SD-3 & $7694-30-6$ & $\mathrm{C}_{16} \mathrm{H}_{16}$ & 208.30 & \\
\hline trans-1,2-diphenyl cyclobutane & SD-4 & 20071-09-4 & $\mathrm{C}_{16} \mathrm{H}_{16}$ & 208.30 & \\
\hline 2,4,6-triphenyl-1-hexene & ST-1 & $18964-53-9$ & $\mathrm{C}_{24} \mathrm{H}_{24}$ & 312.45 & \\
\hline 1a-phenyl-4a-(1'-phenylethyl)tetralin & ST-2 & $26681-79-8$ & $\mathrm{C}_{24} \mathrm{H}_{24}$ & 312.45 & \\
\hline 1a-phenyl-4e-(1'-phenylethyl)tetralin & ST-3 & $26681-79-8$ & $\mathrm{C}_{24} \mathrm{H}_{24}$ & 312.45 & \\
\hline 1e-phenyl-4a-(1'-phenylethyl)tetralin & ST-4 & 26681-79-8 & $\mathrm{C}_{24} \mathrm{H}_{24}$ & 312.45 & \\
\hline 1e-phenyl-4e-(1'-phenylethyl)tetralin & ST-5 & $26681-79-8$ & $\mathrm{C}_{24} \mathrm{H}_{24}$ & 312.45 & \\
\hline 1e,3e,5a-triphenylcyclohexane & ST-6 & $28336-57-4$ & $\mathrm{C}_{24} \mathrm{H}_{24}$ & 312.45 & \\
\hline 1e,3e,5e-triphenylcyclohexane & ST-7 & 28336-57-4 & $\mathrm{C}_{24} \mathrm{H}_{24}$ & 312.45 & \\
\hline
\end{tabular}

서술하였다. ${ }^{20)}$ 간략히 설명하자면, 해수 시료는 시료 채취 현 장에서 $25 \mathrm{~mL} \mathrm{DCM}$ 으로 총 4회 반복하여 추출되어 운반된 약 $100 \mathrm{~mL}$ 추출 용액을 실험실에서 적당하게 교반하여 여과 후, 질소 농축기(model: Turbovap classic II, uppsala, Sweden) 를 사용하여 추출 용액이 $0.75 \mathrm{~mL}$ 가 될 때까지 농축하였고, 여기에 IS $(2 \mathrm{mg} / \mathrm{L}) 30 \mu \mathrm{L}$ 를 가하여 분석 시료로 하고 $\mathrm{GC} / \mathrm{MS}$ 로 분석하였다.

해양 모래 시료의 경우, 모래 $5.0 \mathrm{~g}$ 을 정밀히 달아 분취하고 여기에 $\mathrm{BP}(1 \mathrm{mg} / \mathrm{L}) 30 \mu \mathrm{L}$ 를 주입하였다. 여기에 $\mathrm{DCM}$ 용매
$25 \mathrm{~mL}$ 를 가하고 초음파추출기(model : Sonifier 450, Branson Ultrasonics Corp., Danbury, USA)로 1분간 4회 반복 추출하여 총 $100 \mathrm{~mL}$ 의 $\mathrm{DCM}$ 로 하였다. 이후 수행된 농축 및 분석과정 은 해수 시료의 전처리 방법과 똑같이 수행되었다.

\subsection{GC/MS 분석방법 및 $\mathrm{QA} Q \mathrm{QC}$}

시료을 분석하기 위한 $\mathrm{GC} / \mathrm{MS}$ 는 기체크로마토그래피 $\mathrm{HP} 7820 \mathrm{~A}$ 와 질량분석기 HP 5977B를 사용하였다. 여기에 사 용된 분석용 칼럼은 HP-5 MS capillary column (30 m × 250 


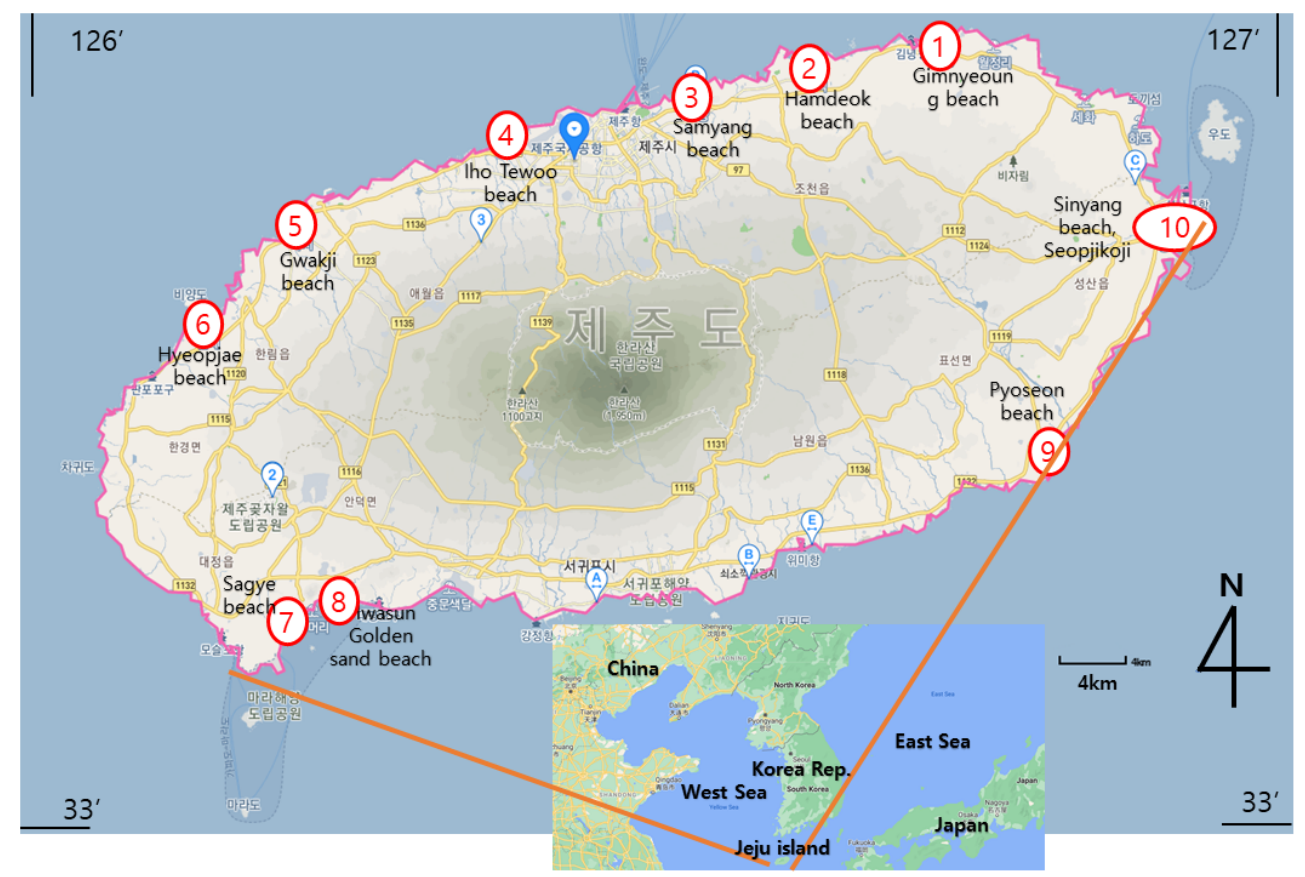

Fig. 1. Map showing the sampling sites of sea water and beach sand of Jeju Island.

$\mu \mathrm{m} \times 0.25 \mu \mathrm{m}$, Agilent, Santa Clara, USA)이고, MS는 전자 이온화 모드에서 $70 \mathrm{eV}$ 로 작동되었다. 인젝터는 splitless $\operatorname{mode}$ 로 $1 \mu \mathrm{L}$ 를 주입하고 온도는 $280^{\circ} \mathrm{C}$ 로 유지하였다. 헬륨 을 Carrier gas로 사용했으며 유량은 $1.4 \mathrm{~mL} / \mathrm{min}$ 으로 일정하 게 유지하였다. 오븐 온도는 먼저 $50^{\circ} \mathrm{C}$ 에서 2 분간 대기하고, 분당 $8^{\circ} \mathrm{C}$ 씩 상승시켜 $258^{\circ} \mathrm{C}$ 까지 도달시킨다. 이후, 분당 $4^{\circ} \mathrm{C}$ 씩 $290^{\circ} \mathrm{C}$ 까지 증가시키고 이를 4 분간 유지하여 총 Run Time 은 40 분으로 설정하였다. MSD transfer line의 온도는 $290^{\circ} \mathrm{C}$, $\mathrm{MS}$ Source 온도는 $300^{\circ} \mathrm{C}$ 로 각각 유지하였다. 분석은 $\mathrm{SIM}$ mode로 분석하였고, SOs와 내부표준물질에 대한 Selected ion 은 이전 연구에서 상세하게 서술하였다. ${ }^{20-24)}$

$\mathrm{SOs}$ 개별 화학종의 검출한계는 $2 \mu \mathrm{g} / \mathrm{L}$ 이하이었고, 이는 $\mathrm{SNR}$ 의 3 배에 해당하는 값으로 결정되었다. 또한, $\mathrm{QA} / \mathrm{QC}$ 를 위해 회수율을 평가하여 분석방법을 검증하였으며, 이때 회수 율은 $80 \sim 120 \%$ 로 나타났다.

이전 연구에서 보도된 바와 같이, 해수와 해사 시료의 SOs 정량에는 IS 평가 실험결과를 기반으로 선정된 내부표준물질 을 바탕으로 내부표준법을 사용하여 정량하였다. 이때 사용된 IS는 SM의 경우에 Acenaphthene-d10 (Ace-d10)을, 1,3-diphenyl propane (SD-1), 2,4-diphenyl-1-butene (SD-3), trans-1,2-diphenyl cyclobutane (SD-4), 2,4,6-triphenyl-1-hexene (ST-1)의 경우에 Phenanthrene-d10 (Phe-d10)을, 1a-phenyl-4e-(1'-phenylethyl) tetralin (ST-3), 1e-phenyl-4e-(1'-phenylethyl) tetralin (ST-5), 1,3,5triphenylcyclohexane-isomer (ST-6 \& ST-7)의 경우에는 4Terphenyl-d14 (4-ter-d14)을 사용하였으며, 선정된 이들 IS로 개별 $\mathrm{SOs}$ 화학종을 정량화하였다.

\section{3. 결과 및 고찰}

\section{1. 제주도 해변 환경에서 $\mathrm{SOS}$ 모니터링}

Table 2와 Fig. 2에서 제시된 바와 같이, SOs 농도는 해수보 다 해사에서 훨씬 높았다. 해변 모래에서 SOs 평균 농도는 최저 $9.80 \mathrm{ng} / \mathrm{g}$ 에서 최대 $13.62 \mathrm{ng} / \mathrm{g}$ 로, 표준편차를 고려하면 해사에서 SOs 농도의 변동성이 상대적으로 크고, 반면 해수에 서 SOs 평균 농도는 일정하게 $0.05 \sim 0.11 \mu \mathrm{g} / \mathrm{L}$ 로 비교적 낮았

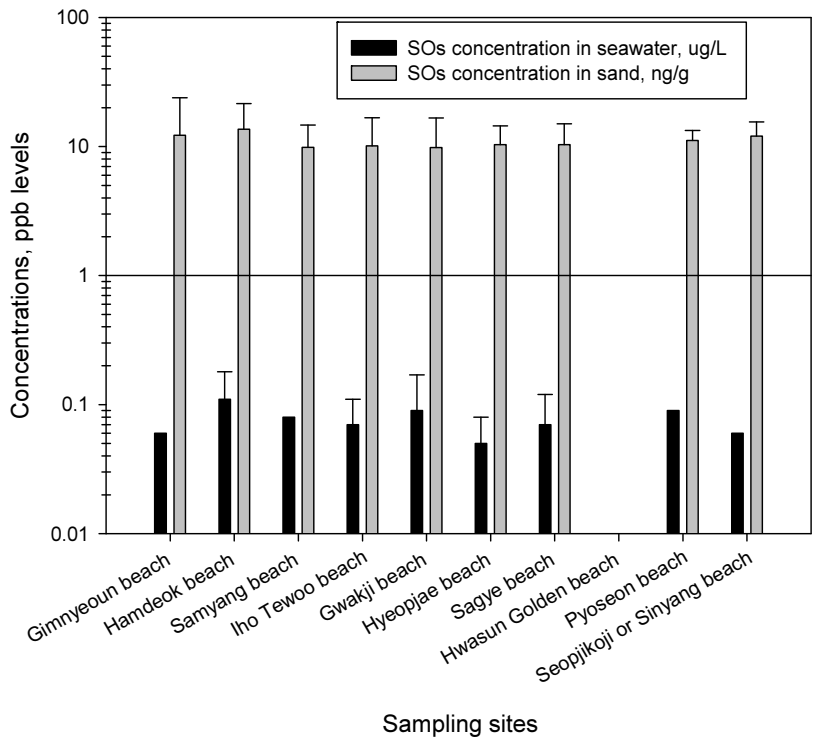

Fig. 2. The concentration of styrene oligomers (SOs) in beach sand samples of Jeju Special Self-Governing Province, Korea Rep. Note that this figure is derived from the data presented in Table 2. 
Table 2. Comparison of styrene oligomers (SOs) concentrations in beach sand and seawater of Jeju Island and Hawaii Islands.

\begin{tabular}{|c|c|c|c|}
\hline Sampling sites & Concentrations of SOs in seawater, & & Concentrations of SOs in beach sand, ng/g \\
\hline Gimnyeoung beach & $0.06(n=2)$ & $<$ & $12.23 \pm 11.63(n=7)$ \\
\hline Hamdeok beach & $0.11 \pm 0.07(n=3)$ & $<$ & $13.62 \pm 7.86(n=6)$ \\
\hline Samyang beach & $0.08(n=2)$ & $<$ & $9.85 \pm 4.83(n=5)$ \\
\hline Iho Tewoo beach & $0.07 \pm 0.04(n=3)$ & $<$ & $10.12 \pm 6.56(n=5)$ \\
\hline Gwakji beach & $0.09 \pm 0.08(n=15)$ & $<$ & $9.80 \pm 6.86(n=21)$ \\
\hline Hyeopjae beach & $0.05 \pm 0.03(n=3)$ & $<$ & $10.33 \pm 4.12(n=8)$ \\
\hline Sagye beach & $0.07 \pm 0.05(n=)$ & $<$ & $10.36 \pm 4.62(n=7)$ \\
\hline Hwasun Golden beach $^{+}$ & - & & - \\
\hline Pyoseon beach & $0.09(n=2)$ & $<$ & $11.12 \pm 2.20(n=5)$ \\
\hline Sinyang beach, Seopjikoji & $0.06(n=2)$ & $<$ & $12.04 \pm 3.50(n=7)$ \\
\hline Hawaii island, Hawaii, USA ${ }^{20)}$ & $57.82\left(18 \text { persons } / \mathrm{km}^{2}\right)^{*}$ & $>$ & 1.42 \\
\hline Maui island, Hawaii, USA ${ }^{20)}$ & $467.41\left(62.5 \text { persions } / \mathrm{km}^{2}\right)^{*}$ & $>$ & 170.4 \\
\hline O’ahu island, Hawaii, USA ${ }^{20)}$ & $0.1\left(617 \text { persons } / \mathrm{km}^{2}\right)^{*}$ & $<$ & 16.07 \\
\hline
\end{tabular}

+ Sample collection stopped due to large-scale port construction.

* Population density.

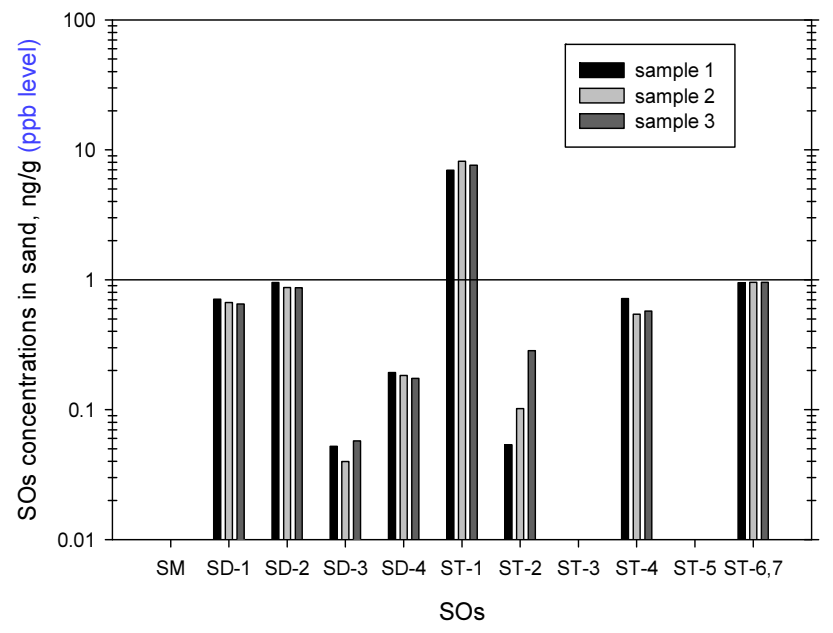

Fig. 3. Examples of distribution of individual styrene oligomer in the sand samples of Gwakji beach in Jeju Special Self-Governing Province, Korea Rep.

고 그 농도의 변동성도 상대적으로 낮았다. 더욱이 제주도 해 변 환경에서 채취된 모든 해수와 해사 시료에서 SOs 화학종 이 검출되었다. 이들 모니터링 결과는 기존 연구 결과들 ${ }^{18,20-24}$ 과 매우 유사한 것으로, SOs 농도는 모래 해안지역에서 채취된 해수보다 해변 모래에서 상당히 높게 모니터링 조사되고 있다. 게다가, Table 2와 Fig. 2에서 제시된 제주도 해양 환경의 $\mathrm{SOs}$ 농도는 기존에 보고된 세계 평균 농도(해사: $3,679 \pm$ $8,199.2 \mathrm{ng} / \mathrm{g}$, 해수: $5.1 \pm 6.4 \mu \mathrm{g} / \mathrm{L})^{18)}$ 보다 훨씬 낮은 것으로 조사되었다. 이들 모니터링 결과로부터 SOs가 모래 입자의 표 면에 비교적 잘 흡착될 수 있음을 암시하는 것으로 여겨진다.

Fig.3은 제주도 협재 해변에서 채취된 모래 시료를 분석한 것으로, 개별 SOs 화학종의 농도별 분포 양상을 나타낸 것이 다. Fig.3에 나타낸 바와 같이, ST-1 > ST-4, ST-6, ST-7, SD-1,
$\mathrm{SD}-2>\mathrm{ST}-2, \mathrm{SD}-3, \mathrm{SD}-4$ 순으로 SOs 의 농도가 감소하는 경 향을 나타냈지만, ST-3, ST-5, SM 이들 화학종은 검출한계 이 하로 나타났다. 하지만 이들 SOs 개별 화학종의 농도 분포 양상은 대개 일정하지 않았고, 채취된 시료에 따라 개별 SOs 농도 분포도 상당히 다르게 나타났다. 하지만 이들 개별 SOs 화학종에 의한 농도 분포를 비교해 보면, 대체로 $\mathrm{ST}>\mathrm{SD}$ $>\mathrm{SM}$ 순으로 그 농도 분포 양상이 뚜렷하게 감소하는 것으로 나타났다. 이 결과는 이전 연구 결과 ${ }^{18,20-24)}$ 와 유사한 경향을 보여주었다.

\section{2. 제주도 해안의 SOs 오염 요인 평가}

Table 2와 Fig. 2에 나타낸 바와 같이, SOs 농도는 해수보다 해사에서 상당히 높았다. 해사에서 SOs 농도는 김녕 해변, 함 덕 해변, 섭지코지 해변이 상대적으로 조금 높았고, 이호테우 해변과 곽지 해변은 상대적으로 조금 낮은 SOs 농도를 보였 다. 이전 연구 ${ }^{18,25)}$ 와 유사하게, 해사에서 $\mathrm{SOs}$ 화학종들이 해 수와 비교하여 상대적으로 매우 높은 농도로, SOs 화학종들이 모래 표면에 더 잘 흡착될 수 있음을 암시한다.

위의 조사 결과는 모래 해변에서 자연적인 풍화 과정을 거 치는 PS 플라스틱에 의한 오염도를 평가하는데 단서를 제공 할 수 있다. 즉, 해변 퇴적물은 PS 플라스틱에서 파생된 SOs 의 발생원을 설명하는 중요한 자료로 사용될 수 있다. 모래 해변에서의 풍화 작용을 통해 침출된 SOs 화학종들은 강우 등에 의해 해변을 거쳐 해수로 유입될 수 있다. ${ }^{24)}$ 비록 상당 부분의 PS 플라스틱 오염이 해안 근처에 퇴적되어 있을지라 도, 소량의 SOs는 해안에 퇴적되지 않고 강우의 흐름에 의해 바다로 이송될 수도 있다.

$\mathrm{SOs}$ 화학종은 PS 플라스틱 뿐만 아니라 스타이렌계 고무 및 수지의 제조하는 과정과 사용하는 과정에서도 대기 환경으 
로 배출될 수 있다. 이런 SOs 화학종 중에서, SM은 일부 나무, 계피, 커피 콩 및 땅콩의 수액과 같은 다양한 식물 종의 천연 성분으로 알려지지만, 상당량이 상업적인 용도로 인해 인공적 으로 대량 생산되고 있다. ${ }^{26)}$ 하지만 현재까지 $\mathrm{SM}$ 을 제외한 다른 SOs 화학종들은 그 용도도 알려지지 않았으며, 자연에서 도 발견되지 않는 인위적인 화학종이다. ${ }^{18,20-24)}$

Table 1에서 나타낸 SOs 화합물에 관한 물리·화학적 성질 도 보고된 바가 없었다. 최근 발표된 Kwon과 Moon (2019) ${ }^{25)}$ 의 SOs의 물리·화학적 특성에 관한 연구 결과에 따르면, $\mathrm{SOs}$ 의 LogKow 값이 3.43 이상, 증기압(vapor pressure)이 1.92 $\times 10^{-3} \mathrm{mmHg}$ 이하, 헨리상수도 $0.26 \times 10^{-3} \mathrm{~atm}-\mathrm{m}^{3} / \mathrm{mol}$ 이하 로, SOs는 모래, 부유성 고체나 침전물 등에 비교적 쉽게 흡착 될 수 있지만 대기 중으로 휘발되는 것은 매우 적을 것으로 추정된다. 게다가, SOs 개별 화학종이 환경으로 배출되면 $\mathrm{SM}$ 을 제외하고 대부분의 SOs는 물에 대한 용해도가 낮아서 주 로 모래와 같은 토양 매체에 잔류할 것으로 예측된다. 결과적 으로, 해변 환경에서 SOs는 이동성이 매우 낮고 대기 중으로 휘발될 가능성도 매우 낮을 것으로 예측된다.

Table 2의 SOs 모니터링 결과와 이들 화학종의 이동성이 제한적이어서, SOs는 버려진 $\mathrm{PS}$ 의 표면에서 침출되어 주로 모래에 흡착되고, 이 중에서 일부 SOs가 강우 등에 의해 해수 로 제한적으로 이송될 수 있다. ${ }^{24)}$ 결과적으로, 해변에서 SOs 검출은 해당 해변의 환경오염을 유발하는 인자이자 오염 원인 을 평가하는 지표로 사용될 수 있다.

Table2에 제시된 바와 같이, 조사된 제주도 해안의 SOs 농 도가 해당 해변별로 해수보다 해사에서 최저 약 109배(해사/ 해수 SOs 농도 비율, 곽지 해변)에서 최대 약 207배(협재 해 변)로 높게 검출되었다. Kwon et al. $(2018)^{20)}$ 에 따르면, 이 결 과는 제주도의 주요 해변이 주로 제주도 해변의 모래 오염에 의한 내부 요인에 의해 이들 해변이 오염될 수 있음을 의미한 다. 곽지 해변 < 함덕 해변, 삼양 해변, 표선 해변 < 이호테우 해변, 사계 해변 < 섭지코지 해변, 김녕 해변, 협재 해변 순으 로 내부 요인에 의한 해변 오염도가 클 것으로 생각된다. 이런 환경오염을 유발하는 내부 요인으로 인간의 활동과 밀접한 관계가 있을 것으로 생각된다. ${ }^{20,21)}$ 즉, $\mathrm{PS}$ 플라스틱은 현대 인간의 생활에서 필수품이 되었기 때문에 SOs 농도는 인구 밀도와 인구 이동(여행객 수 등)과도 밀접한 관련이 있다. ${ }^{20}$ 이는 향후 좀 더 면밀한 연구가 필요할 것으로 생각된다.

\section{3. 제주도 해변과 미국 하와이주 섬의 SOs 오염도 비교 평가}

Table2는 제주도 주요 해변과 미국 하와이 주에 속한 3곳의 섬에서 모니터링된 SOs 농도를 보여준다. 앞서 언급한 바와 같이, 제주도 해변은 해수보다 해사에서 SOs 농도가 높았고, 이는 제주도 내부 요인에 의해 해변이 주로 오염될 수 있음을 보여주었다.

제주도 해변과 달리, 하와이주에 부속된 섬 중 가장 큰 섬인
하와이섬(Hawaii island)은 해사보다 해수에서 약 41 배 높은 농도로 SOs가 검출되었고, 마우이섬(Maui island)도 약 3배 높은 농도로 SOs가 검출되었다(Table 2). 이것은 섬 내부 요 인보다 해수를 통한 외부 요인에 의해 해변이 오염될 수 있음 을 보여준다.

특히, 미국의 하와이주의 섬들은 태평양에서 시계방향으 로 회전하는 해류에 따라 미국 서부 해안과 함께 각종 버려 진 플라스틱이 직접적으로 모이는 곳으로, 흔히 북태평양 쓰 레기 집합 구역(North Pacific Garbage Patch, NPGP)에 위치 한 곳으로 널리 알려져 있다. ${ }^{20,21)}$ 하와이섬과 마우이섬은 18 명 $/ \mathrm{km}^{2}, 62.5$ 명 $/ \mathrm{km}^{2}$ 각각 인구 밀도가 낮고 공장도 없어서 해사의 SOs 농도가 비교적 낮았다. ${ }^{20)}$ 하지만 이들 지역의 해수에서 SOs 농도는 해사에서보다 더 많이 높았기 때문에, 아마도 대부분의 SOs 화학종들이 태평양에 접해 있는 외부 지역에서 유입된 것으로 생각된다. 즉, PS 플라스틱이나 PS 플라스틱에서 침출된 SOs 화학종들이 외부 요인인 해류와 기상 요인에 의해 하와이섬과 마우이섬에 도달하는 것으로 짐작된다.

한편, Table 2에 제시된 바와 같이, 오아후섬(O'ahu island)은 해수보다 해사에서 약 161 배 높은 농도로 SOs가 검출되었는 데, 이는 주로 오아후섬 내부 요인에 의해 해변이 오염될 수 있음을 암시한다. 하와이섬과 마우이섬에 비해 오아후섬의 인 구 밀도는 $1 \mathrm{~km}^{2}$ 당 617 명으로 상대적으로 매우 높다. ${ }^{20)}$ 더욱 이, 높은 인구 밀도를 갖는 오아후섬은 하와이주 정부가 위치 한 곳으로 호놀룰루 국제공항, 와이키키 해변(Waikiki beach) 등 대규모 관광집단시설이 위치하고 있다(www. google.com). 상 대적으로 오아후섬은 외부 요인보다는 사람에 의한 내부 요인 이 클 것으로 추정된다.

\section{4. 결 론}

이 연구의 목적은 제주도 연안 환경의 오염을 유발하는 내· 외부 요인을 평가하는 것이었다. 제주도 해변의 해사에서 SOs 평균 농도는 최저 $9.80 \mathrm{ng} / \mathrm{g}$ 에서 최대 $13.62 \mathrm{ng} / \mathrm{g}$ 으로, 해수에 서 SOs 평균 농도는 일정하게 $0.05 \sim 0.11 \mu \mathrm{g} / \mathrm{L}$ 로 비교적 낮았 다. 이 결과는 제주도의 주요 해변이 주로 제주도 내부 요인 (예, 인구 밀도, 인구 이동에 따른 여행객 수 등)에 의해 오염 될 수 있음을 의미한다. 곽지 해변 < 함덕 해변, 삼양 해변, 표선 해변 < 이호테우 해변, 사계 해변 < 섭지코지 해변, 김녕 해변, 협재 해변 순으로 내부 요인에 의한 해변 오염도가 클 것으로 예상된다. 이 연구가 제주도 해안 환경의 플라스틱 오 염을 줄이는 정책에 활용되길 기대해 본다.

\section{Acknowledgement}

This work was supported by the National Research Foundation of Korea (NRF) grant funded by the Korea government (MSIT) 
(No. 2021R1F1A1056355). In addition, the authors wish to acknowledge a grand-in-aid for research from Gwangju Green Environment Center (Research No. 20-02-40-41-12).

\section{References}

1. R. C. Thompson, Y. Olsen, R. P. Mitchell, A. Davis, S. J. Rowland, A. W. G. John, D. McGonigle, A. F. Russell, Lost at sea: Where is all the plastics?, Science, 304, 838(2004).

2. C. J. Moore, Synthetic polymers in the marine environment: A rapidly increasing, long-term threat, Environ. Res., 108(2), 131-139(2008).

3. D. H. An, J. G. Kim, Proposing Policy for the Prevention of Marine Pollution from Microplastics, Journal of environmental policy and administration, 26(3), 77-102(2018).

4. J-J. Ko, Y-T. Jo, J-H. Park, K. Moon, B. G, Kwon, Study on the qualitative analysis of styrene oligomers originated from styrene-based plastic polymer materials, J. Korean Soc. Environ. Eng., 41(5), 278-285(2019).

5. PlasticsEurope, https://www.plasticseurope.org, (2018).

6. J. R. Jambeck, R. Geyer, C. Wilcox, T. R. Siegler, M. Peryman, A. Andrady, R. Naravan, K. L. Law, Plastic waste inputs from land into the ocean, Science, 347(6223), 768-771(2015).

7. S. Avery-Gomm, P. D. O'Hara, L. Kleine, V. Bowes, L. K. Wilson, K. L. Barry, Northern fulmars as biological monitors of trends of plastic pollution in the eastern North Pacific, Mar. Pollut. Bull., 64(9), 1776-1781(2012).

8. M. Thiel, I. A. Hinojosa, L. Miranda, J. F. Pantoja, M. M. Rivadeneira, N. Vásquez, Anthropogenic marine debris in the coastal environment: A multi-year comparison between coastal waters and local shores, Mar. Pollut. Bull., 71(1-2), 307-316(2013).

9. A. Bakir, S. J. Rowland, R. C. Thompson, Enhanced desorption of persistent organic pollutants from microplastics under simulated physiological conditions, Environ. Pollut., 185, 16-23(2014)

10. J. G. B Derraik, The pollution of the marine environment by plastic debris: a review, Mar. Pollut. Bull., 44(9), 842-852 (2002).

11. D. W. Laist, Overview of the biological effects of lost and discarded plastic debris in the marine environment, Mar. Pollut. Bull., 18(6), 319-326(1987).

12. A. A. Koelmans, E. Besseling, A. Wegner, E. M. Foekema., Plastic as a carrier of POPs to aquatic organisms: a model analysis, Environ Sci. Technol., 47(14), 7812-7820(2013).

13. R. E. Engler, The Complex Interaction between Marine Debris and Toxic Chemicals in the Ocean, Environ. Sci. Technol., 46(22), 12302-12315(2012).

14. P. G. Ryan, A simple technique for counting marine debris at sea reveals steep litter gradients between the Straits of Malacca and the Bay of Bengal, Mar. Pollut. Bull., 69(1-2), 128-136(2013).

15. A. L. Andrady, Microplastics in the marine environment,
Mar. Pollut. Bull., 62(8), 1596-1605(2011).

16. L. Hermabessiere, A. Dehaut, I. Paul-Pont, C. Lacroix, R. Jezequel, P. Soudant, G. Duflos, Occurrence and effects of plastic additives on marine environments and organisms: A review, Chemosphere, 182, 781-793(2017).

17. A. A. Koelmans, E. Besseling, E. M. Foekema, Leaching of plastic additives to marine organisms, Environ. Pollut., 187, 49-54(2014).

18. B. G. Kwon, K. Koizumi, S-Y. Chung, Y. Kodera, J-O. Kim, K. Saido, Global styrene oligomers monitoring as new chemical contamination from polystyrene plastic marine pollution, J. Hazard. Mater., 300, 359-367(2015).

19. K. L. Law, S. E. Moret-Ferquson, D. S. Goodwin, E. R. Zettler, E. DeForce, T. Kukulka, G. Proskurowski, Distribution of surface plastic debris in the Eastern Pacific Ocean from an 11-year data set, Environ. Sci. Technol., 48(9), 4732-4738(2014).

20. B. G. Kwon, S-Y. Chung, S-S. Park, K. Saido, Qualitative assessment to determine internal and external factors influencing the origin of styrene oligomers pollution by polystyrene plastic in coastal marine environments, Environ. Pollut., 234, 167-173(2018).

21. B. G. Kwon, K. Saido, K. Koizumi, H. Sato, N. Ogawa, S-Y. Chung, T. Kusui, Y. Kodera, K. Kogure, Regional distribution of styrene analogues generated from polystyrene degradation along the coastlines of the North-East Pacific Ocean and Hawaii, Environ. Pollut., 188, 45-49(2014).

22. K. Saido, K. Koizumi, H. Sato, N. Ogawa, B. G. Kwon, S-Y. Chung, T. Kusui, M. Nishimura, Y. Kodera, New analytical method for the determination of styrene oligomers formed from polystyrene decomposition and its application at the coastlines of the North-West Pacific Ocean, Sci. Total Environ., 473-474, 490-495(2014).

23. B. G. Kwon, K. Amamiya, H. Sato, S-Y. Chung, Y. Kodera, S-K. Kim, E. J. Lee, K. Saido, Monitoring of styrene oligomers as indicators of polystyrene plastic pollution in the North-West Pacific Ocean, Chemosphere, 180, 500-505 (2017).

24. K. Amamiya, K. Saido, S-Y. Chung, T. Hiaki, D. S. Lee, B. G. Kwon, Evidence of transport of styrene oligomers originated from polystyrene plastic to oceans by runoff, Sci. Total Environ., 667, 57-63(2019).

25. B. G. Kwon, K. Moon, Physicochemical properties of styrene oligomers in the environment, Sci. Total Environ., 683, 216-220(2019).

26. https://wwwn.cdc.gov/TSP/substances/ToxSubstance.aspx?to xid=74, September(2021).

\section{Declaration of Competing Interest}

This authors dclare that they have no known competing financial interests or personal relationships that could have appeared to influence the work reported in this paper. 


\section{Authors and Contribution Statement}

\section{Bum Gun Kwon}

Department of Bioenvironmental \& chemical Engineering, Chosun College of Science \& Technology, Associate Professor, ORCID (0) 0000-0002-5571-9093, Supervision, investigation, data curation, methodology, sampling, writing-reviewing and editing, visualization, original and final draft preparation.

\section{Jae-Jun Ko}

Department of Environmental \& Energy Engineering, Chonnam National University, M.S. Student, ORCiD 다 0000-0002-2381-3464, Methodology, data acquisition and analysis.

\section{Jeong-Hun Park}

Department of Environmental \& Energy Engineering, Chonnam National University, Professor, ORCiD (1) 0000-0002-0661-0059, Data acquisition and analysis, reviewing 